\title{
Research Paper \\ The Buffering Role of Affective-Collective Investment in the Relationship Between Job Stress and Emotional Exhaustion
}

\author{
${ }^{*}$ Mohsen Golparvar ${ }^{1}$ (1), Somayeh Safari² (1)
}

1. Associate Professor, Department of Industrial and Organizational Psychology, Faculty of Educational Sciences \& Psychology, Isfahan (Khorasgan) Branch, Islamic Azad University, Isfahan, Iran.

2. MA, Department of Industrial and Organizational Psychology, Faculty of Educational Sciences \& Psychology, Isfahan (Khorasgan) Branch, Islamic Azad University, Isfahan, Iran.

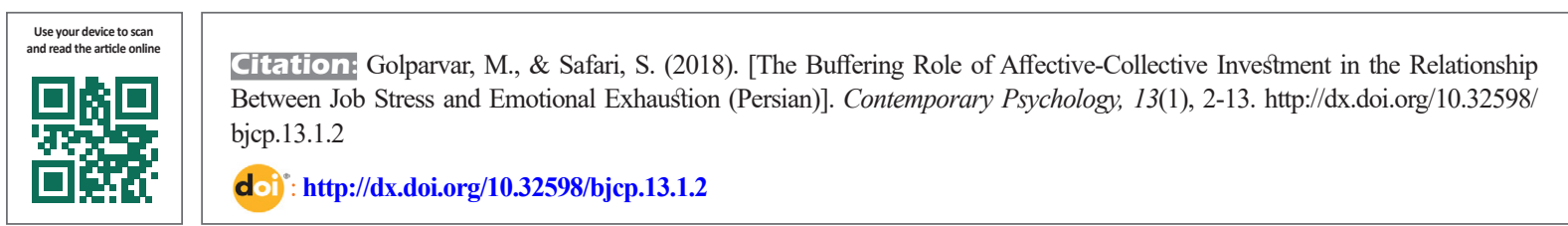

\section{(c) (i) (8)}

Received: 10 Jul 2017 Accepted: 17 Jan 2018 Available Online: 21 Mar 2018

Key words: Job stress, Affectivecollective investment, Emotional exhaustion Industry employees

\section{ABSTRACT}

Objectives Collective investment is one of the novel constructs in the field of soft human capital. It holds potential to capture the effects of adverse occupational and environmental events on human health and its behaviors. This new construct can be implemented in a collective environment. In this research, the relationship between job stress and emotional exhaustion was studied, due to the mediating role of affective-collective investment with three components; collective investment on the promotion of positive effect in others, collective investment on the promotion of feeling of energy in others, and collective investment on the promotion of happiness in others.

Methods According to the purpose of the study, 202 respondents completed the job stress questionnaire, the emotional exhaustion questionnaire and the affective-collective investment questionnaire.

Results There is a positive significant relationship between job stress and emotional exhaustion $(P<0.01)$, but a negative significant relationship between job stress and emotional exhaustion with affective-collective investment $(\mathrm{P}<0.01)$. Results of structural equation modeling and mediation analysis (Bootstrap Test) indicated that affective-collective investment is a complete mediator on the relationship between job stress and emotional exhaustion.

Conclusion Overall, the findings of this research showed that through reinforcement of affective-collective investment, we can prevent the negative effects of occupational stress on human health and its burnout in the workplace.

\section{* Corresponding Author:}

Mohsen Golparvar, PhD.

Address: Department of Industrial and Organizational Psychology, Faculty of Educational Sciences \& Psychology, Isfahan (Khorasgan) Branch, Islamic Azad University, Isfahan, Iran.

Tel: +98 (31) 35354001

E-mail: drmgolparvar@gmail.com 


\title{
نقش ضربهَير سرمايهَذارى جمعى عاطفى در رابطه استرس با فرسودَّى هيجانى
}

\author{
(1) 'محسن كليرور' (1)، سميه صفرى *
}

ا - دانشيار، كروه روانشناسى صنعتى و سازمانى، دانشكده علوم تربيتى و روانشناسى، واحد اصفهان (خوراسكان)، دانشعاه آزاد اسلامي، اصفهان، ايران.

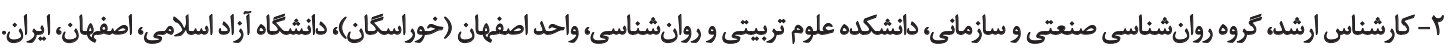

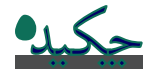

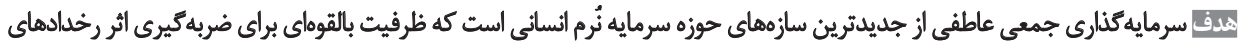

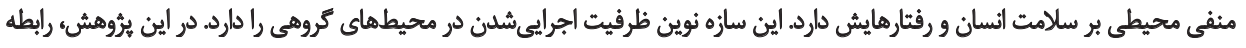

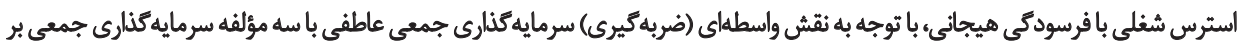

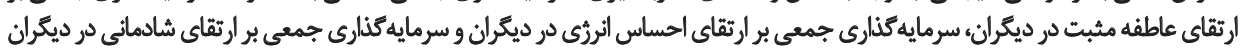
مطالعه شد.

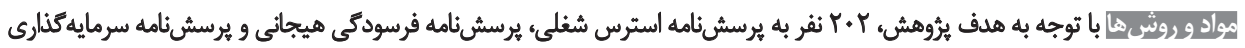
جمعى عاطفى باسخ دادند.

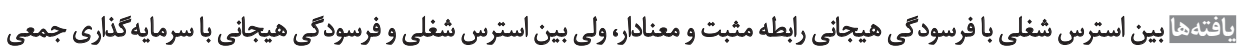

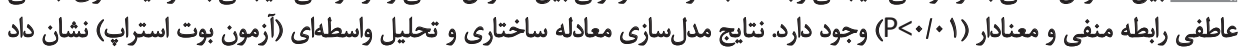

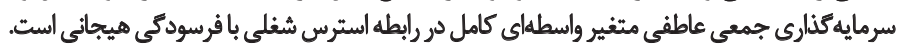

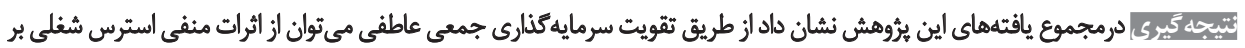

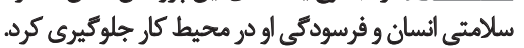

تاريخ دريافت: 19 تير \$ \$ 19

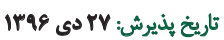

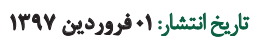

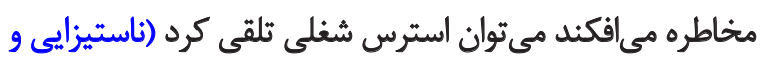

dale.

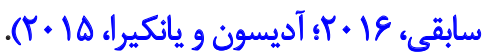

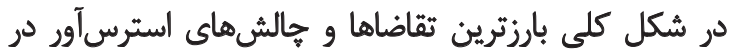

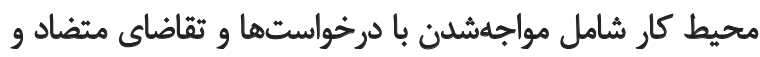

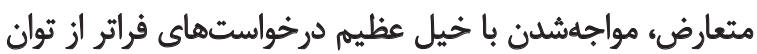

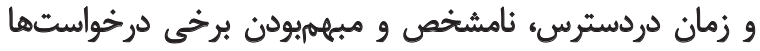

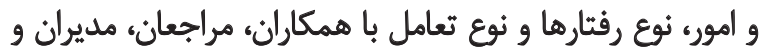

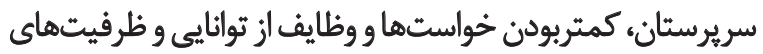

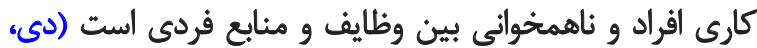

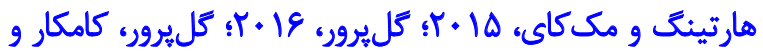

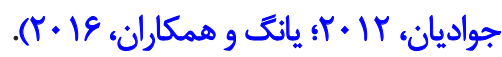

تاكنون يُيامدهاى باواسطه و بيىواسطه مختلفى براى استرس

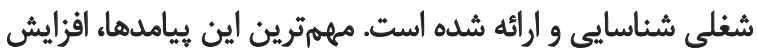

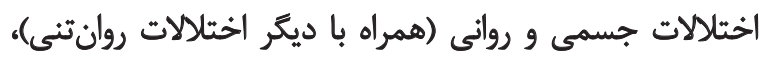

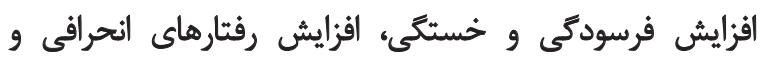

سازمان جهانى بهداشت استرس را الواكنشى كه انسان در هنكام

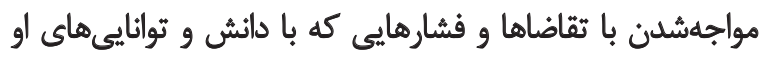

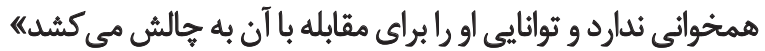

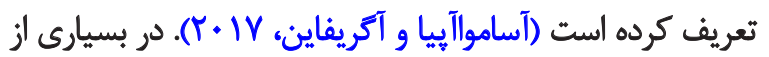

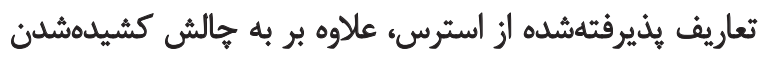

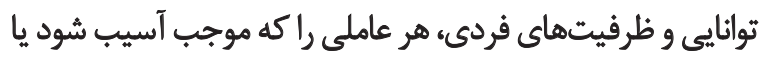

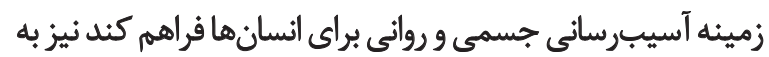

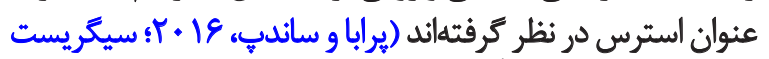

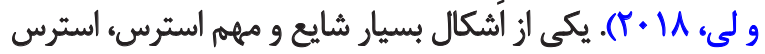

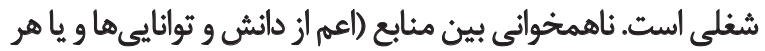

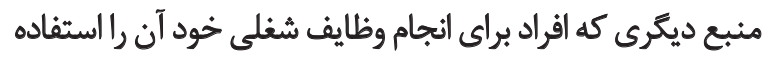

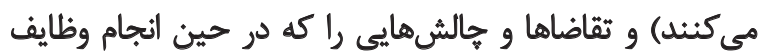

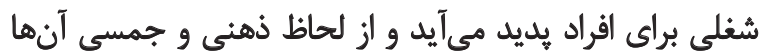

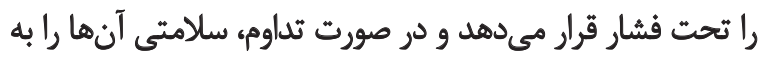

\section{-}

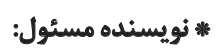

دكتر محسن عل يرود

نشانىي: اصفهان، دانشكاه آزاد اسلامى، واحد اصفهان (خوراسكان)، دانشكده علوم تربيتى و روانشئاسى، كروه روانشناسى صنعتى و سازمانى.

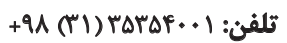

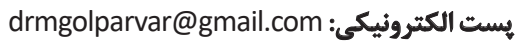




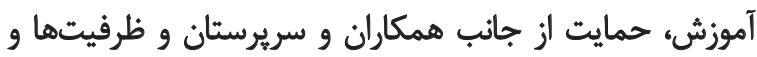

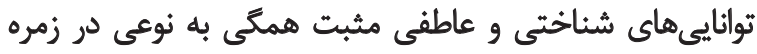

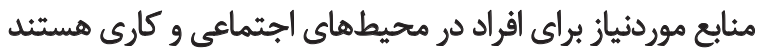

$$
\text { (كل يرور، 19 +r). }
$$

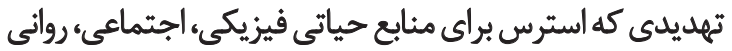

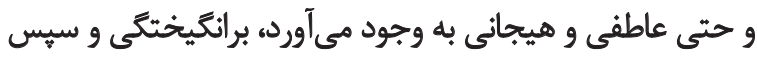

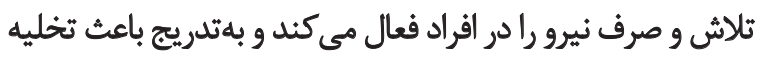

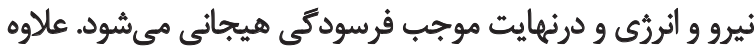

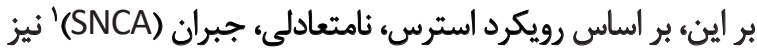

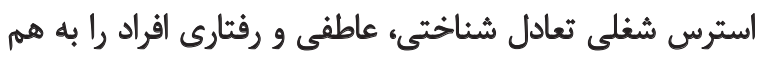

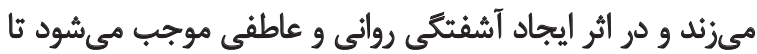

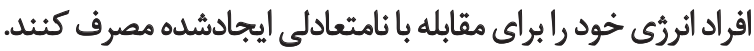

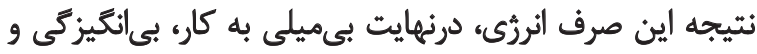

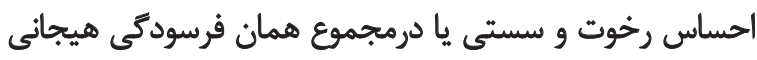

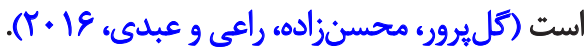
در هر دو نظريه منابع بقا و استرس، نامتعادلى، جبران، استرس

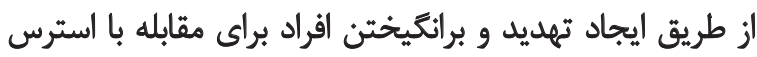

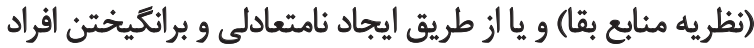

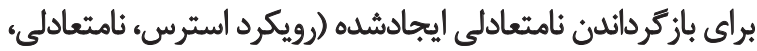

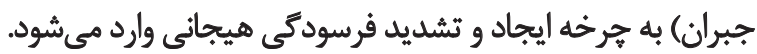

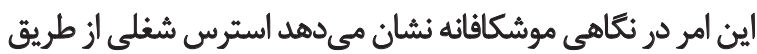

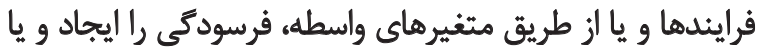

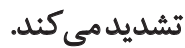

اين بيشبينى در مطالعات مختلف با نشاندادن اينكه با

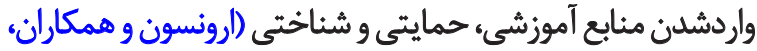

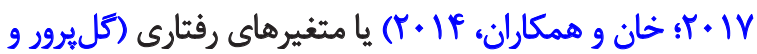

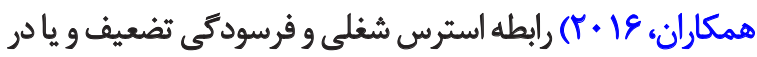

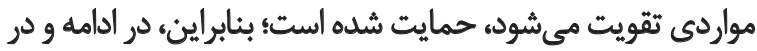

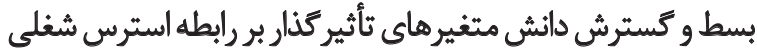

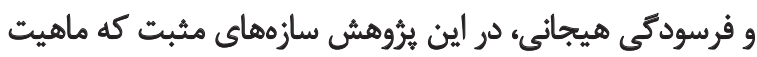

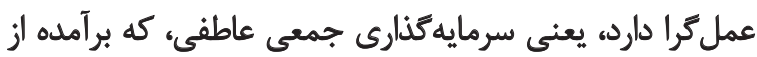

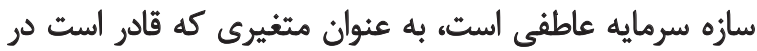

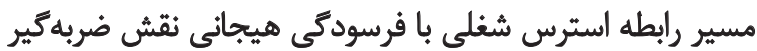

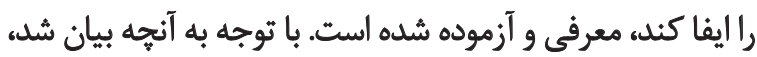

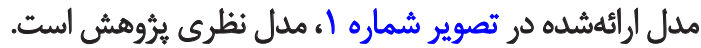
در اين ثروهش درباره رابطه استرس شغلى و فرسودگى

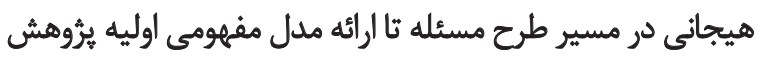

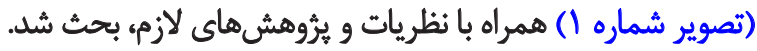

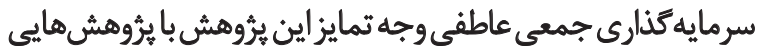

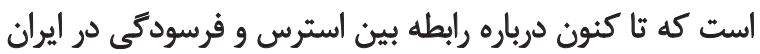

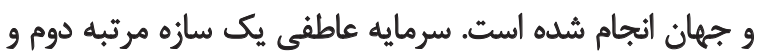

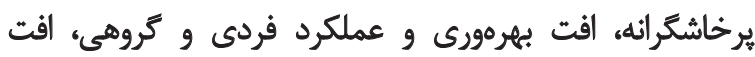

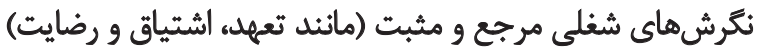

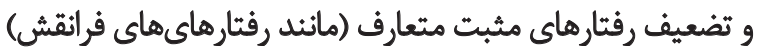

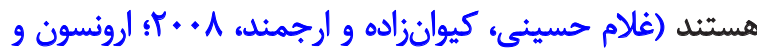

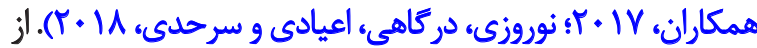

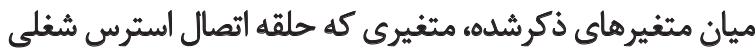

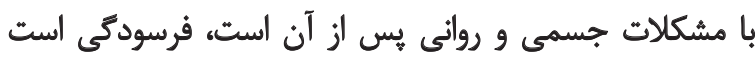

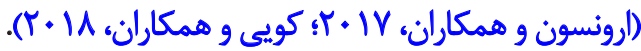
رويكرد سلمؤلفهاى به فرسودتى شغلى، شامل افت كارايى

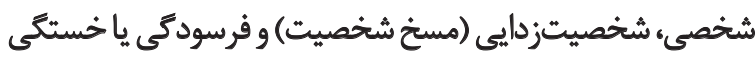

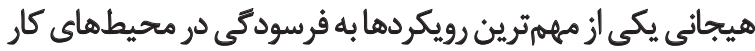

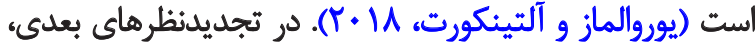

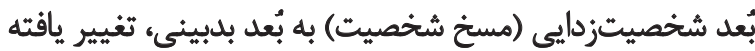

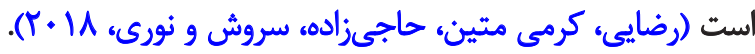

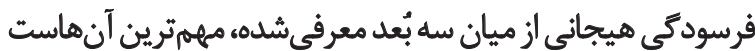

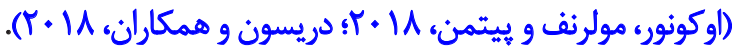

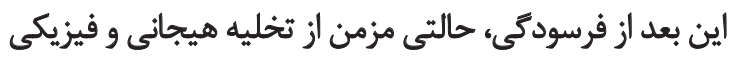

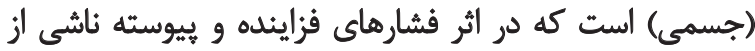

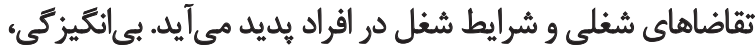

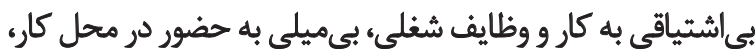

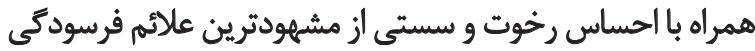

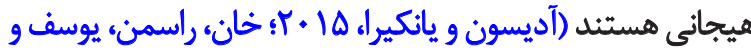

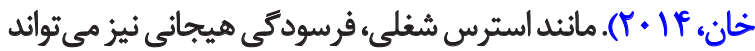

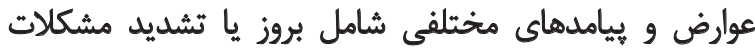

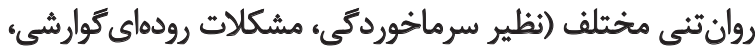

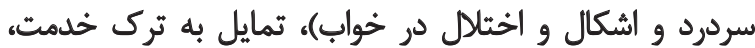

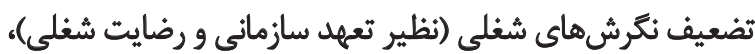

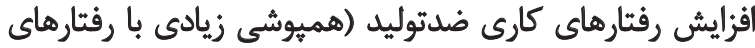

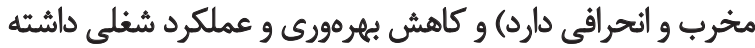

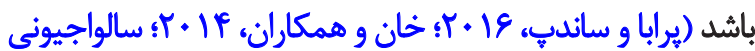

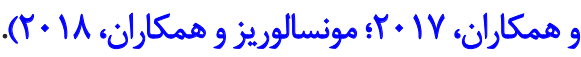

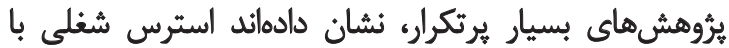

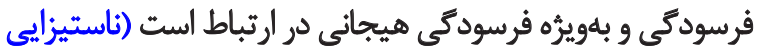

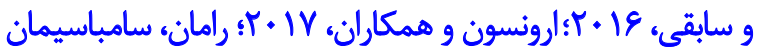

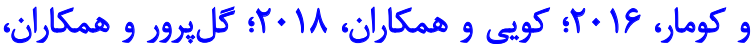

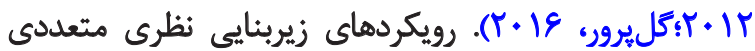

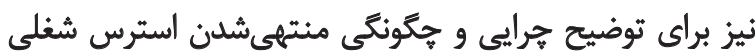

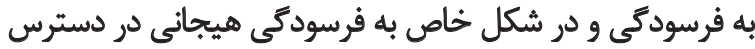

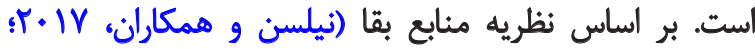

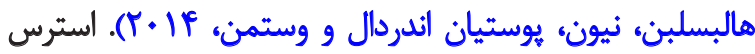

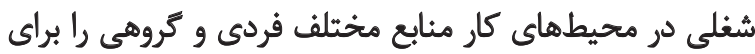

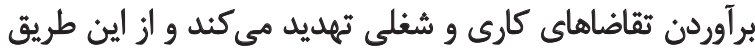

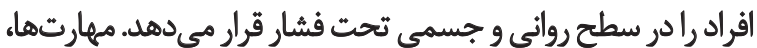




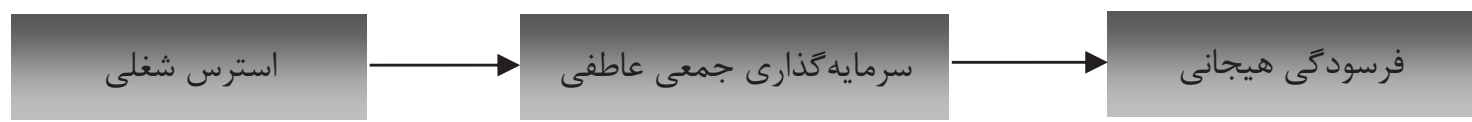

عاطفى با استرس شغلى و فرسودتى هيجانى فراهم مى آورند.

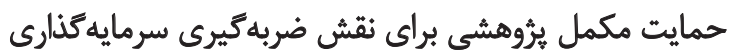

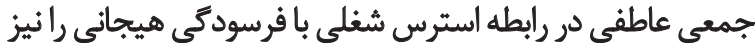

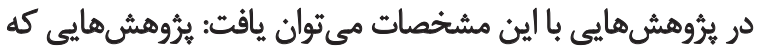

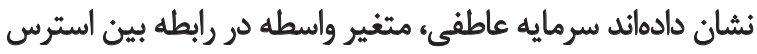

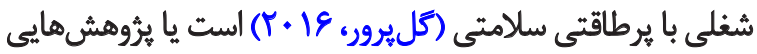

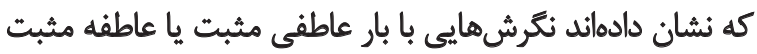

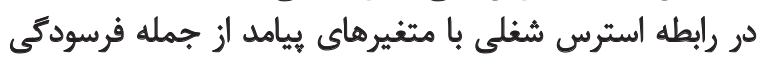

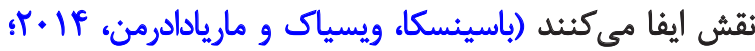

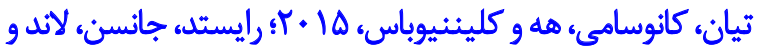

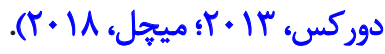

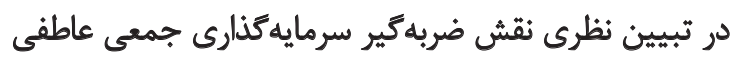

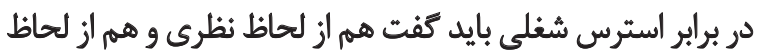

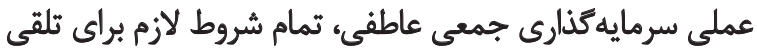

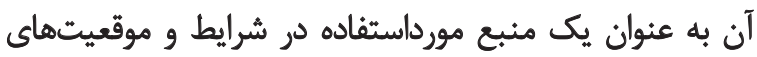

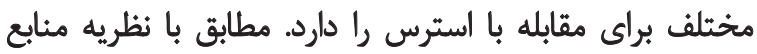

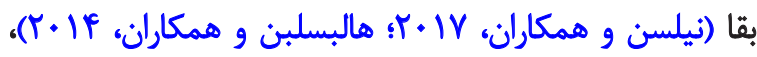

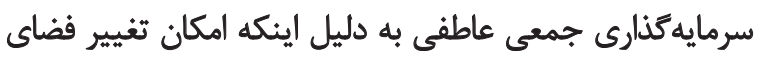

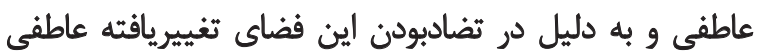

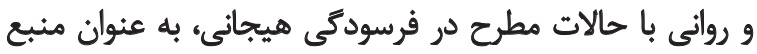

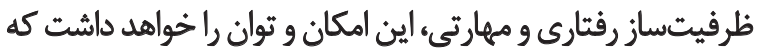

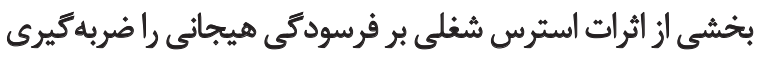

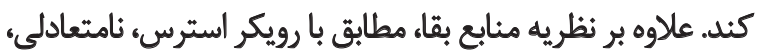

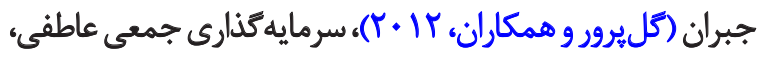

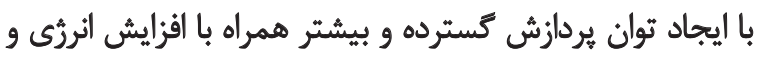

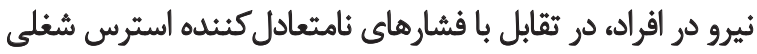

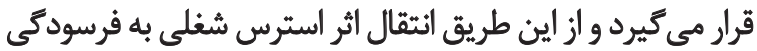

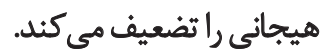

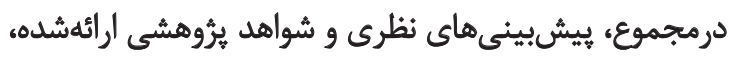

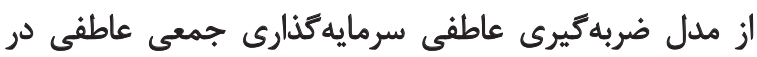

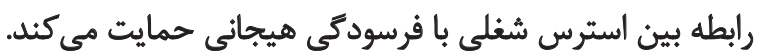

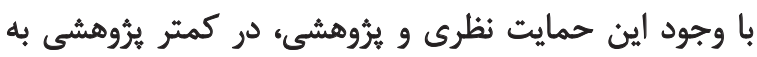

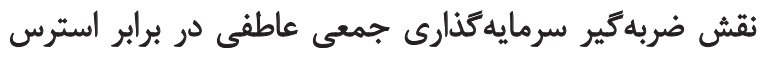

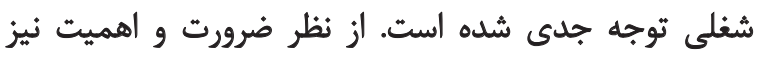

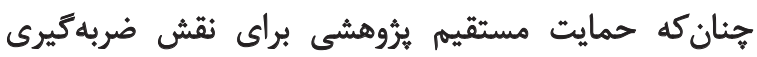

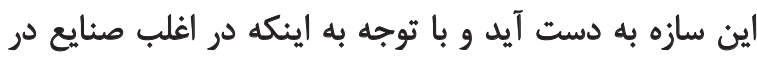

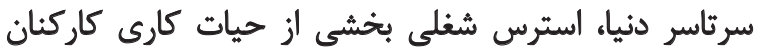
است، در اين صورت مىتوان در مسير عملياتى دازى إنى و ترويج كاركنان
عبارت است از حالتى از نشاط و جوشش عاطفى مثبت درونى كه

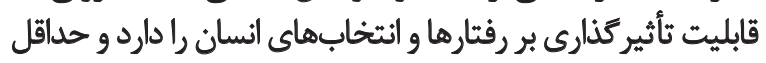

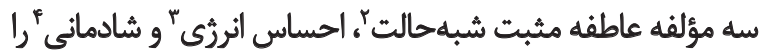

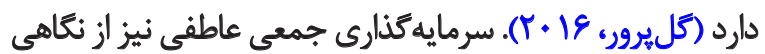

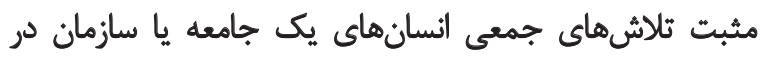

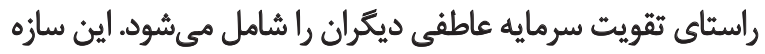

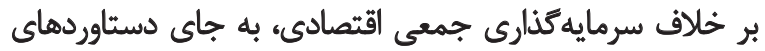

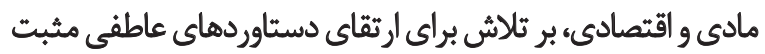

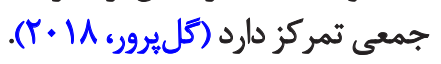

از لحاظ نظرى سرمايهئذارى جمعى عاطفى نسبت به

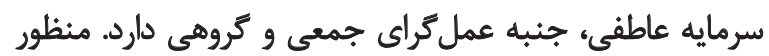

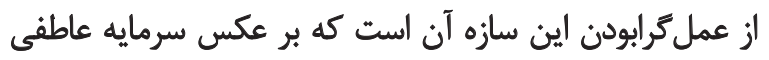

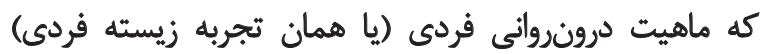

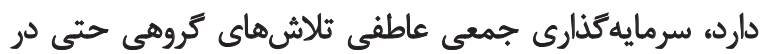

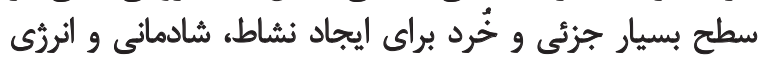

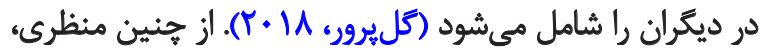

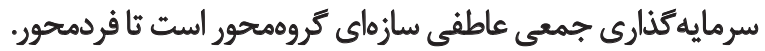

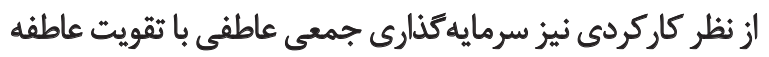

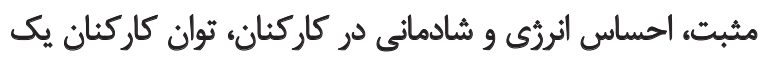

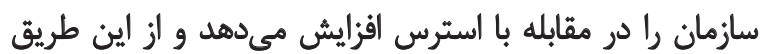

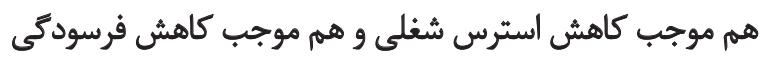

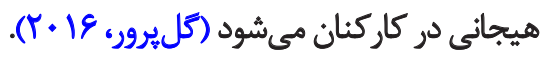

در حمايت از اين نظر، مطالعات ستارخانى مقدمى (Y) (Y) (Y) (Y)،

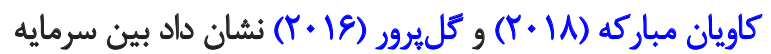

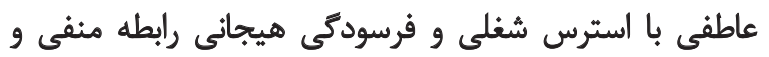

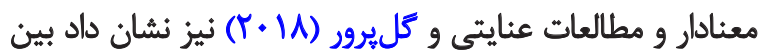

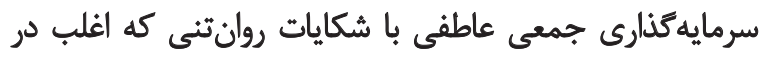

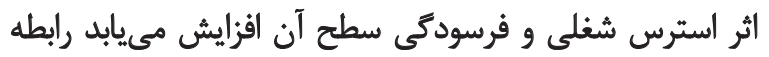

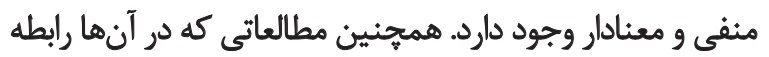

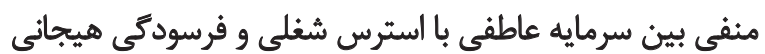

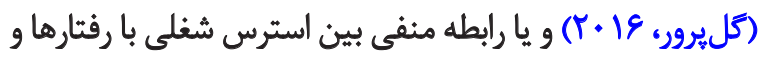

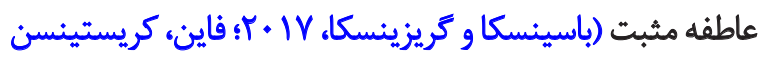

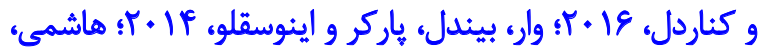

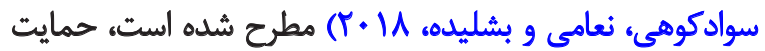

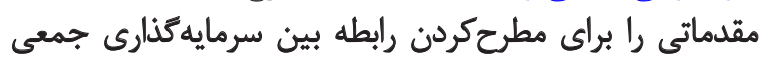

2. State like positive affect

3. Feeling of energy

4. Happiness 
يروسشنامه با رفثتارهاى انحرافى، رابطه مثبت و معنادار و آلفاى براي

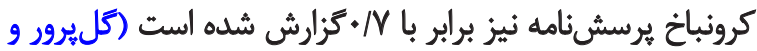

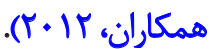

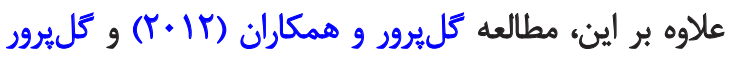

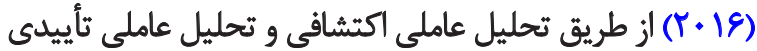

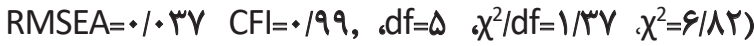

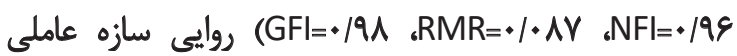

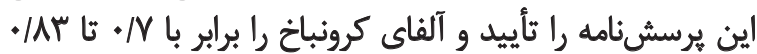

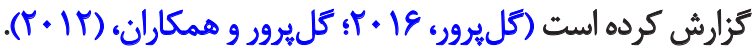

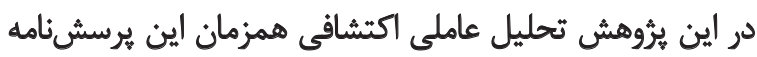

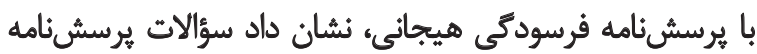

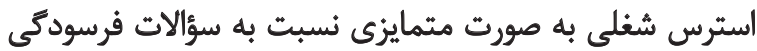

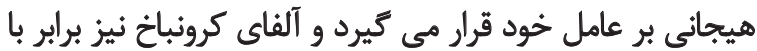

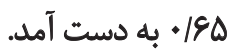

\section{يرسشنامه فرسودكى هيجانى"}

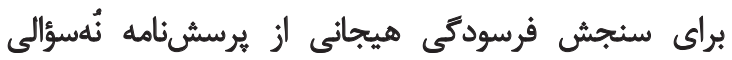

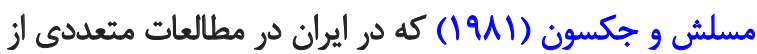

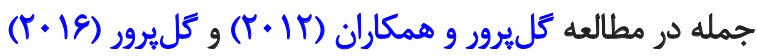

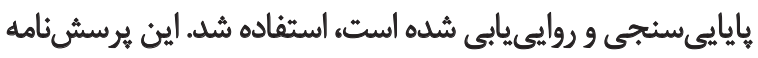

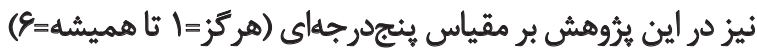

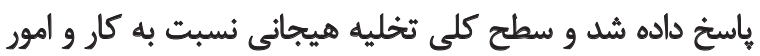

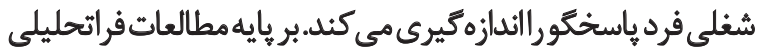

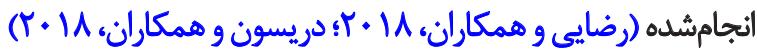

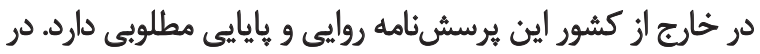

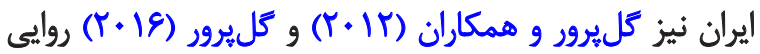

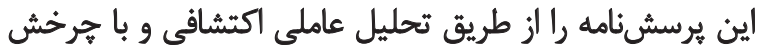

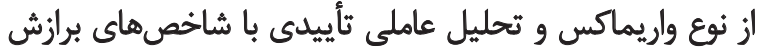

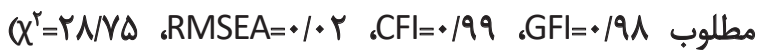

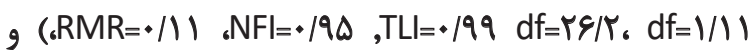

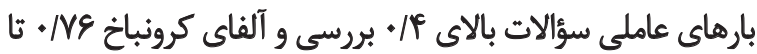
191 / رابراي اين برسشنامه كزارش كردهاند.

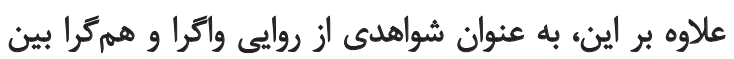

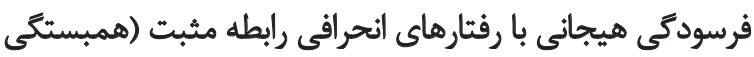

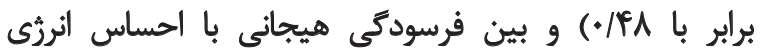

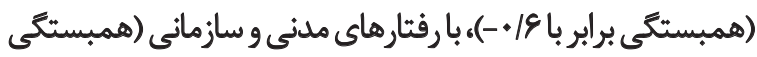

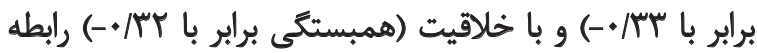

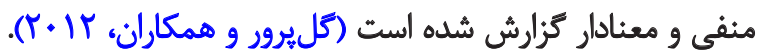

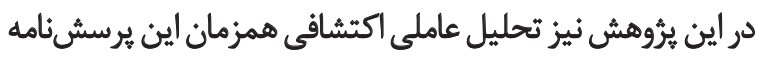

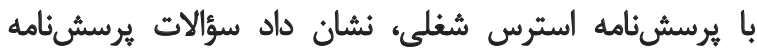

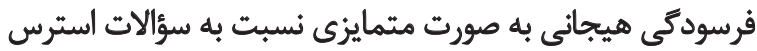

6. Emotional Exhaustion Questionnaire (EEQ)
رفتارها و تثلاشهاى معطوف به سرمايه تذارى جمعى عاطفى؛

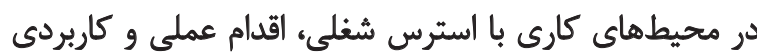

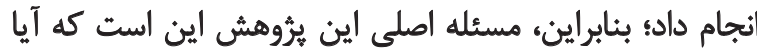

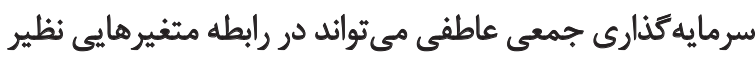

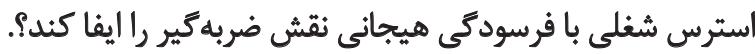

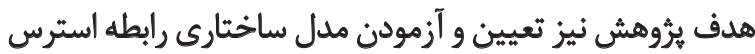

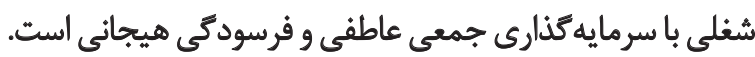

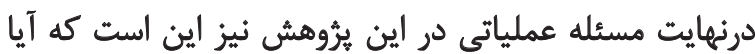

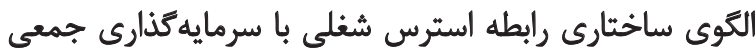

عاطفى و فرسودگى هيجانى برازش مطلوبى با دادهها دارد؟

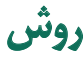

\section{جامعه آماري، ثموثله وروش اجراى بُووشش}

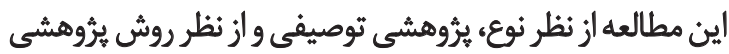

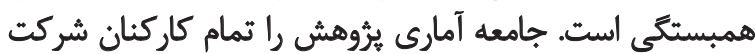

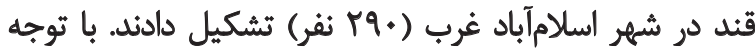

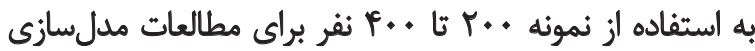

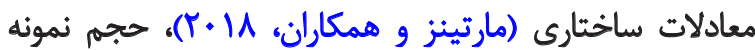

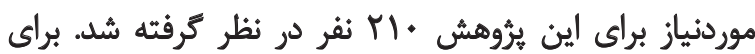

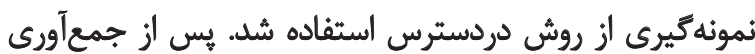

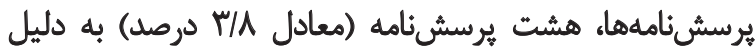

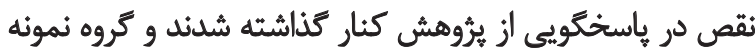

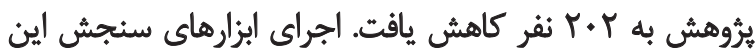

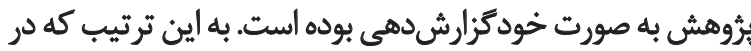

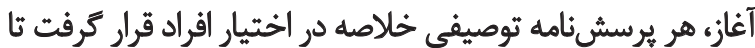

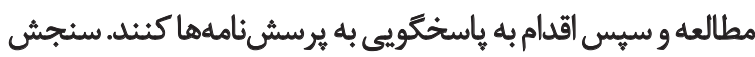

متغيرهاى يُروهش با استفاده از ابزارهاى زير انجام شده است.

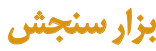 \\ يرسش نامه استرس شغلىه}

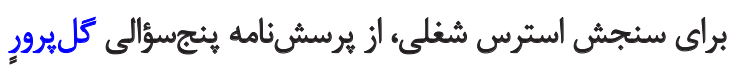

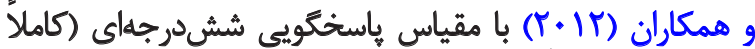

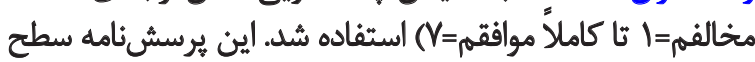

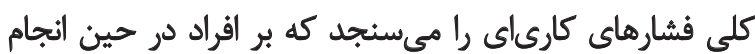

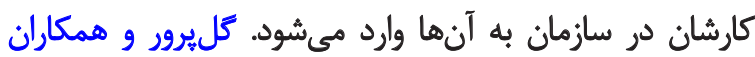

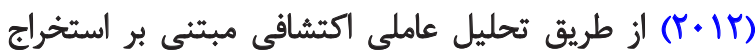

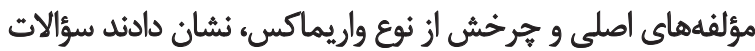

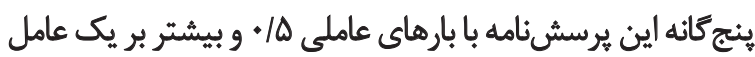

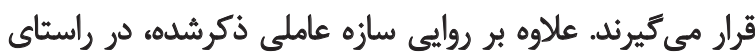

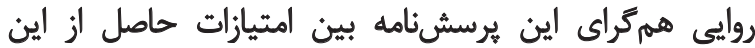


(P<>/ همبستكى مثبت و معنادار و آلفاى كرونباخ برابر با

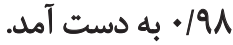

در تحليل دادهها از ضريب همبستخى بيرسون و مدل مازي

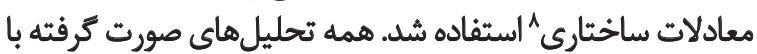

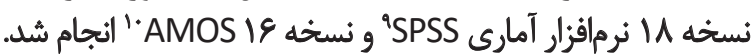

يافتهها

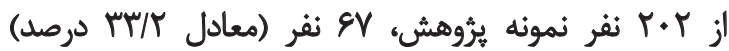

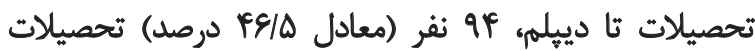

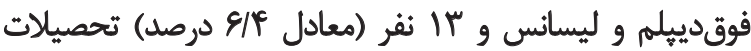

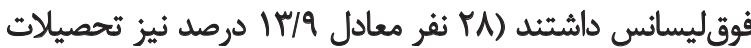

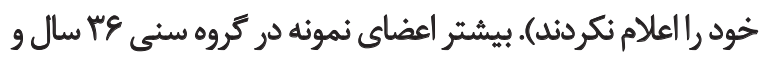

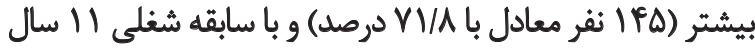

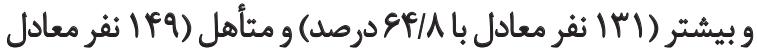

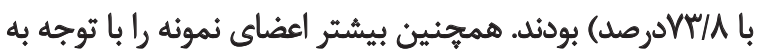

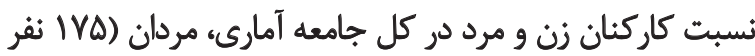

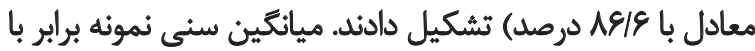

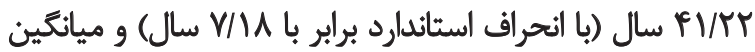

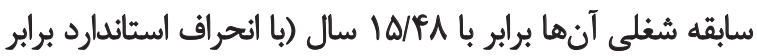

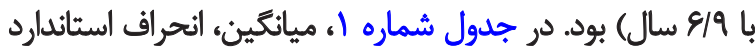
و همبستكى (بيرسون) بين متغيرهاى يرؤهش ارائه شده است. جنانكه در جدول شماره ا مشاهده مي شوده، بين استرس

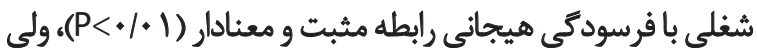

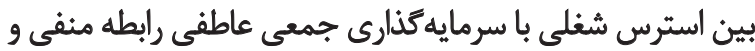

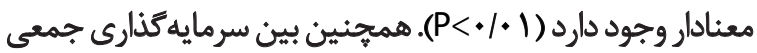

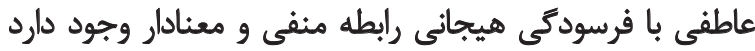

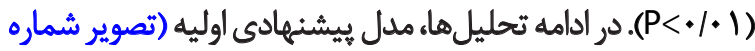

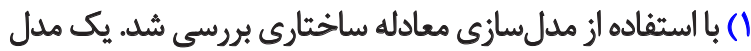

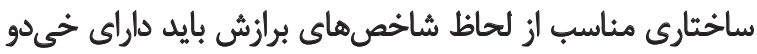

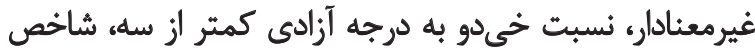

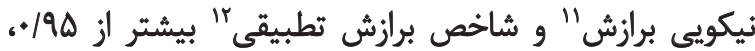

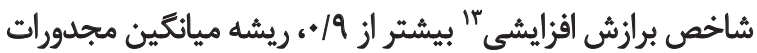

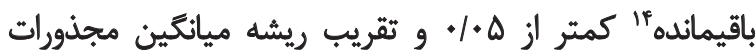

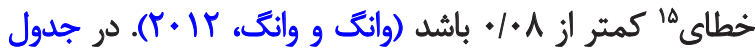

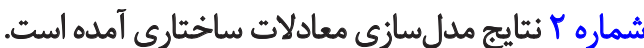

8. Structural Equation Modeling (SEM)

9. Statistical package for social science (Version 18)

10. Analysis of Moment Structures (AMOS)

11. Goodness of Fit Index (GFI)

12. Comparative Fit Index (CFI)

13. Incremental Fit Index (IFI)

14. Root Mean Square of Residual (RMSR)

15. Root Mean Square of Error Approximation (RMSEA)
شغلى بر عامل خود قرار مى كيرند و آلفاى كرونباخ نيز برابر با مباء . به دست آملد.

\section{يرسشنامه سر مايهكذارى جمعى عاطفى"}

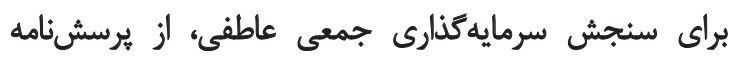

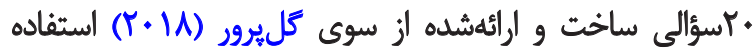

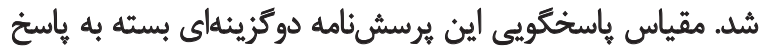

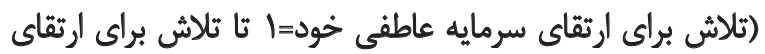

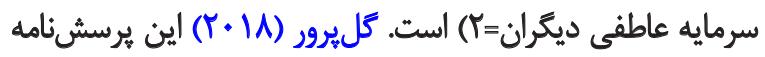

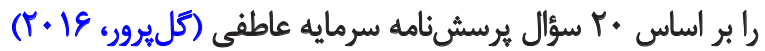

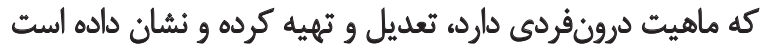

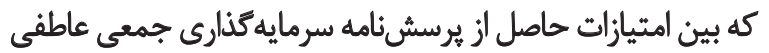

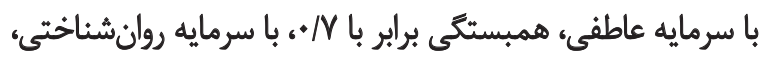

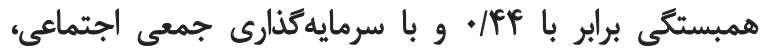

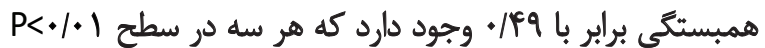

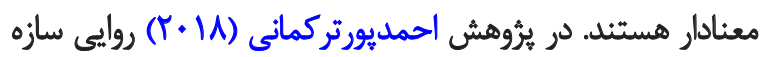

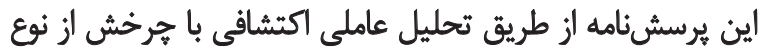

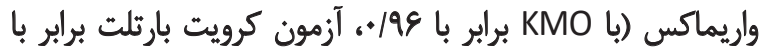

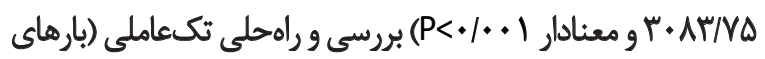

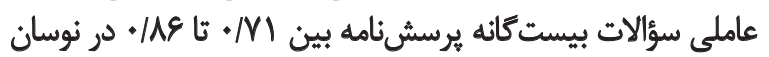

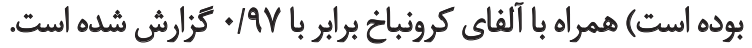

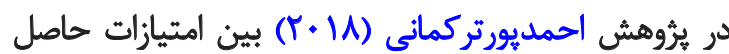

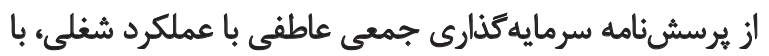

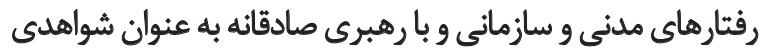

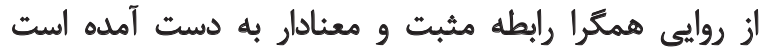

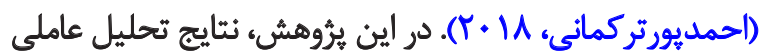

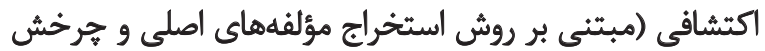

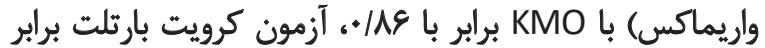

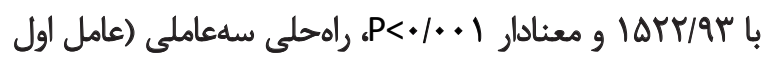

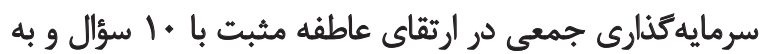

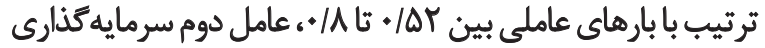

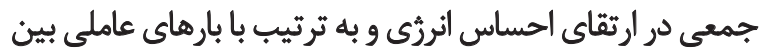

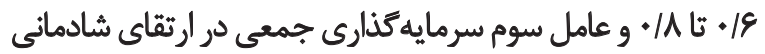

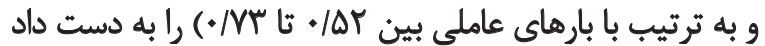

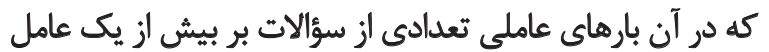

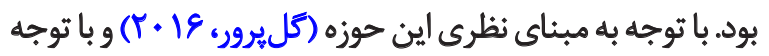

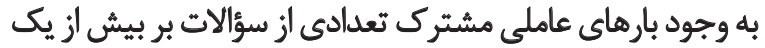

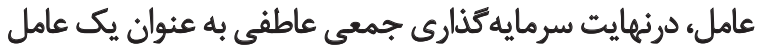

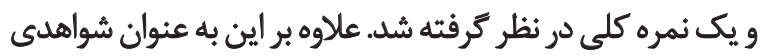

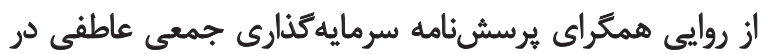

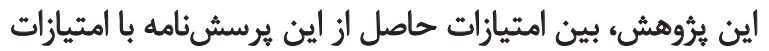

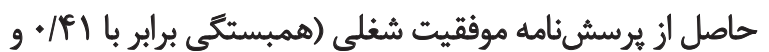

7. Affective-Collective Investment Questionnaire (ACIQ) 
جدول ا. ميانكين، انحراف استاندارد و همبستكى بين متغيرهاى يثروهش

\begin{tabular}{|c|c|c|c|c|}
\hline$r$ & 1 & انتحراف استاندارد & مياتكين & متغيرهاى يثروهش \\
\hline & - & $\cdot / 19 q$ & $r / N$ & استرس شغلى \\
\hline- &.$/ \Delta r$ & $\cdot / N$ & $r / \Lambda \Delta$ & فرسودگى هيجانى \\
\hline.$- / N^{m *}$ & $-\pi /$ pe &.$/ 19$ & $1 / 1 e$ & سر مايه كذارى جمعى عاطلفى \\
\hline
\end{tabular}

دوفصلنامه وزايشناسى معاصر

"ضريب در سطح 1٪/ معنادار است.

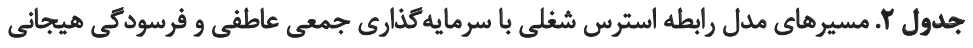

\begin{tabular}{|c|c|c|c|c|c|c|}
\hline $\mathrm{R}^{2}$ & $\mathbf{p}$ & $\mathbf{t}$ & SE & $\beta$ & b & مسير هاى مدل \\
\hline ./Mrq & $.1 . .1$ & $-e / M^{*}$ & 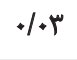 & $-\bullet / \Delta V^{*}$ & $-+119^{*}$ & استرس شغلى ـ سرمايهكذارى جمعى عاطفى \\
\hline.$P V$ & $.1 .+1$ & $-ه / \varphi_{*} *$ & - /pa & $-\bullet / 94 *$ & $r / \Delta \Delta^{*}$ & سرمايه كألرى جمعى عاطفي ـ فرسودكى هيجاني \\
\hline
\end{tabular}

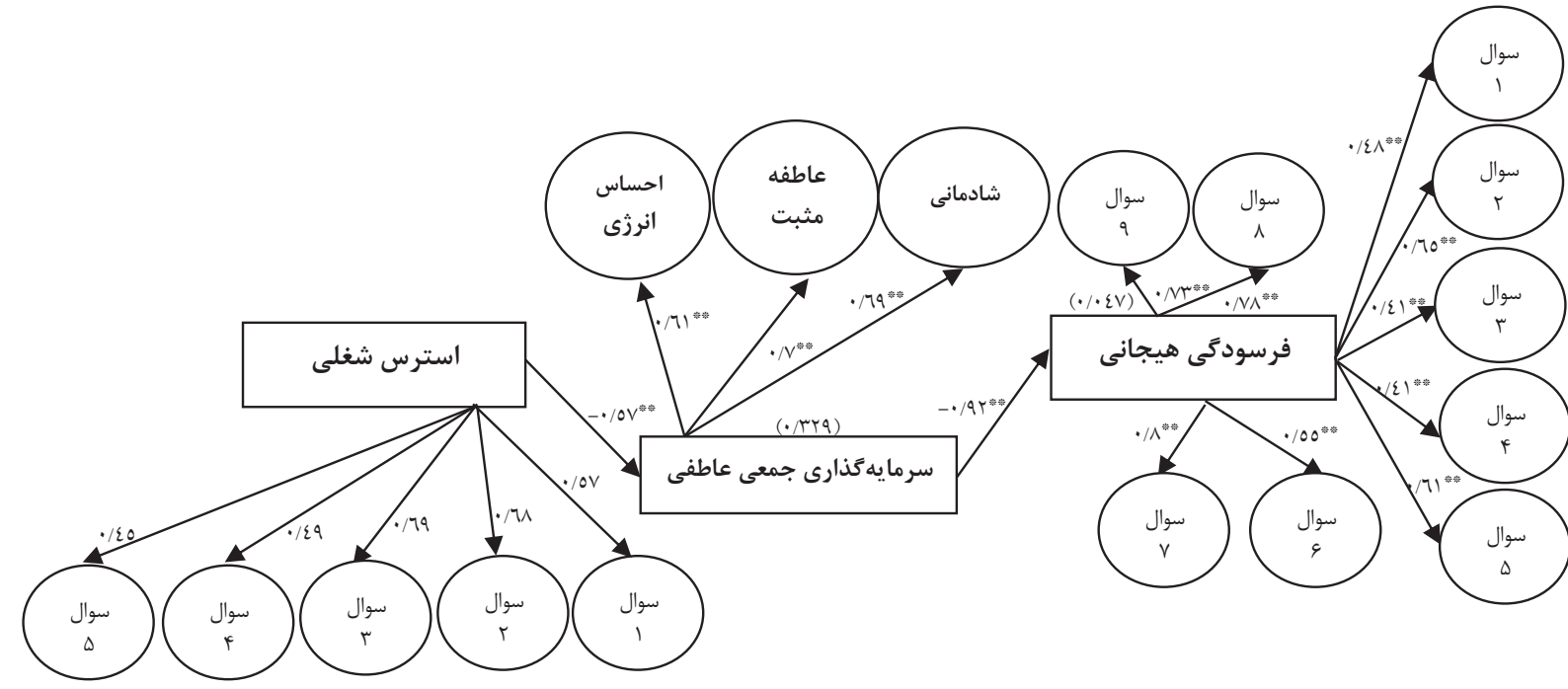

دوفصلنامه وزانشناسى معاصر

تصوير r. الكوى ساختارى نهايى ثئروهش بر حسب ضرايب استاندارد

** $\mathrm{P}<\cdot / \cdot 1$

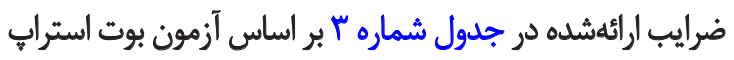

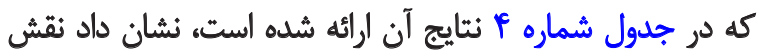

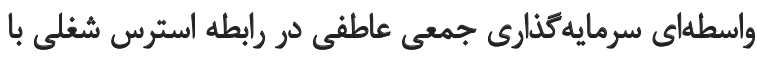

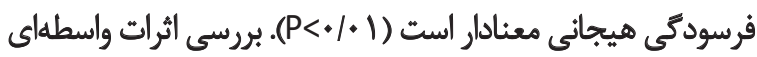

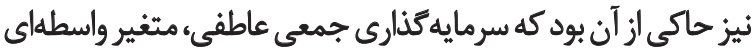

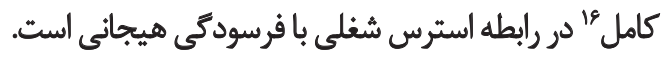

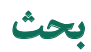

اين هيروهش كه با هدف بردسى رابطه استرس شغلى با باني

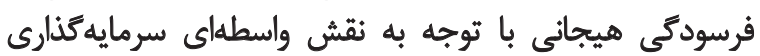

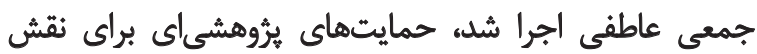

16. Complete mediator
جنان كه در جدول شماره Y مشاهده مىشود، استرس شغلى

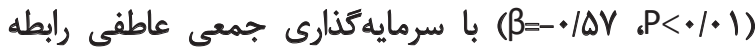

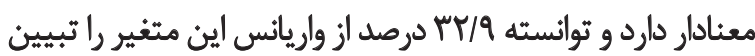

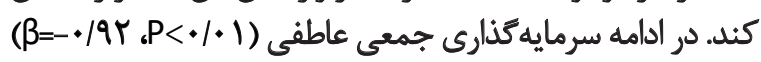

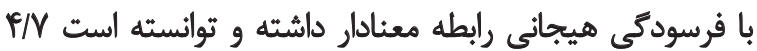

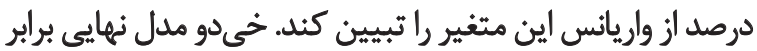

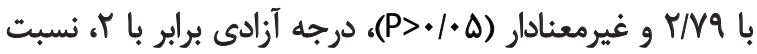

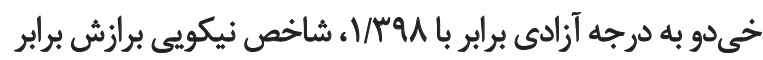

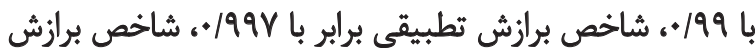

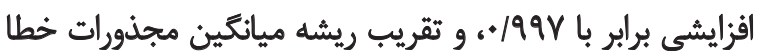

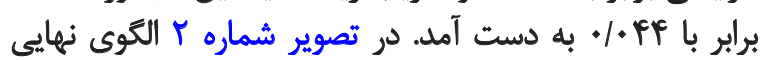

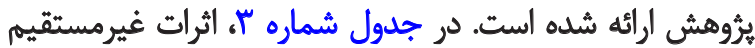

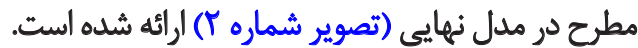


جدول ץ. اثرات غيرمستقيم مطرح در مدل نهايى يثروهش در حالت استاندارد و غيراستاندارد

\begin{tabular}{|c|c|c|c|c|}
\hline $\mathbf{P}$ & $\mathrm{t}$ & استاندلارد & غيراستائلارد & اثرات غيرمستقيم \\
\hline $.1 .+1$ & p/pr* &.$/ \Delta M E *$ &.$/ P V^{*}$ & اثر غيرمستقيم استرس شعلى بر فرسودكى هيجاني از طريق سرمايهكذارى جمعي عاطفى \\
\hline
\end{tabular}

جدول ج. نتايج أزمون بوت استراب درباره نقش واسطهاى سرمايه كذارى جمعي عاطفي در رابطه استرس شغلي با فرسودكى هيجاني

\begin{tabular}{|c|c|c|c|c|c|c|}
\hline حد بالا & حد يايين & خطاى استثاندارد & سوكيرى & بوت & Losls & هسير \\
\hline.$/ 9 \%$ & $\cdot 11 \cdot 1$ &.$/ M I$ & $1.1 \%$ & . &.$/ A r$ & 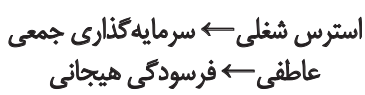 \\
\hline
\end{tabular}

دوفصلنامه روانشناسى معاصر

آماده مقابله مؤثر مي كند.

مدل نظرى يُروهش نيز مبتنى بر رابطه زنجيرهاى بين استرس

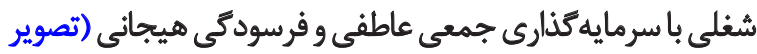

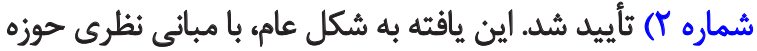

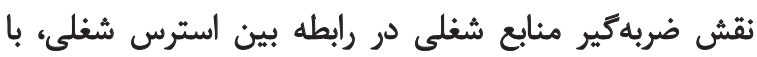

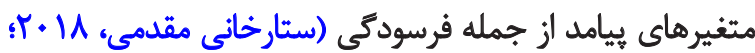

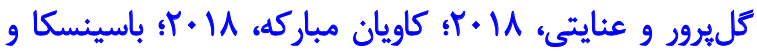

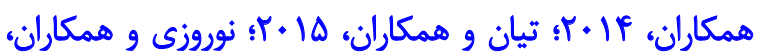

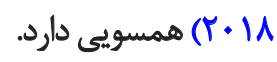

سرمايه كذارى جمعي عاطفي مطابق با بنيان هاي نظرى نيرومند

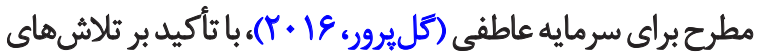

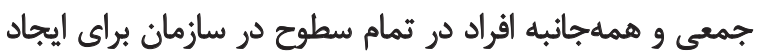

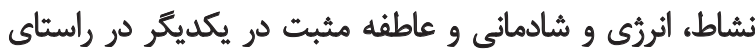

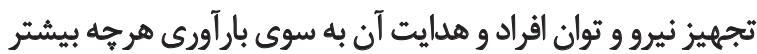

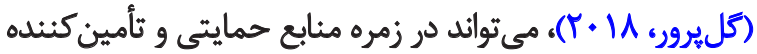

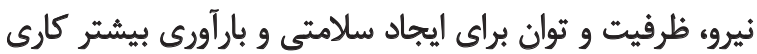

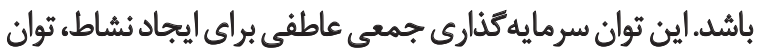

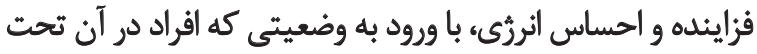

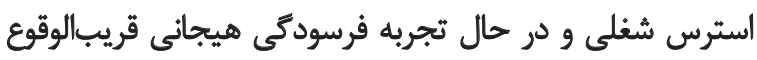

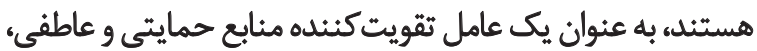

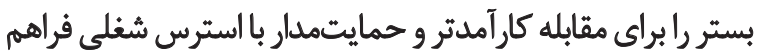
مي كند واز اين طريق رابطه استرس شغلي با فرسودئي هيجاني

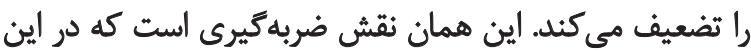

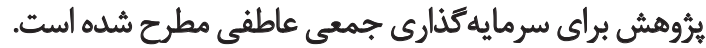
در ادامه تبيينهاي نظرى يافتهها، بايد به دو نكته توجه شود.

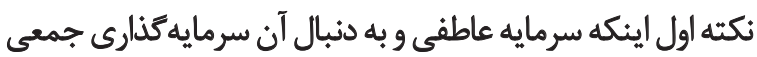

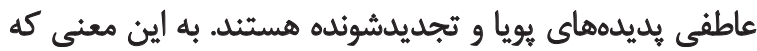

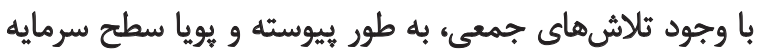

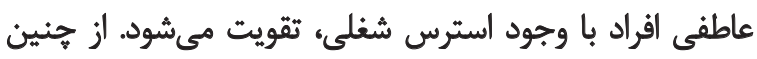

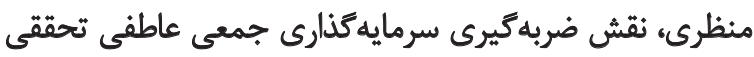

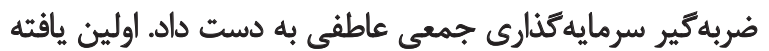

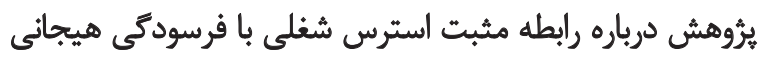

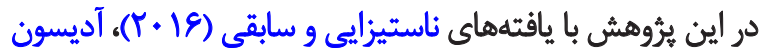

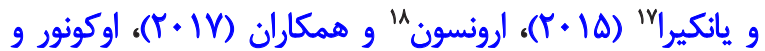

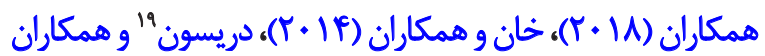
(Y.11)

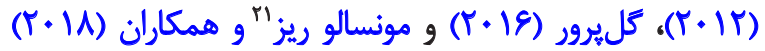
درباره رابطه مثبت بين استرس شغلى با فرسودئى و فرسودئى

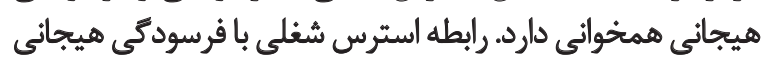

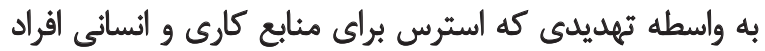

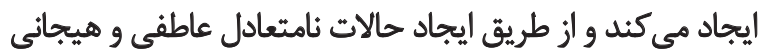

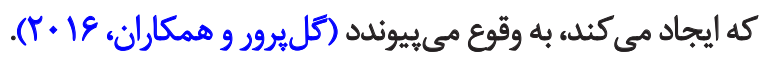
يافته بعدى يثروهش به رابطه منفى سرمايه كنارى جمعى عاطفى با استرس شغلى و فرسودكى هيجانى ارتباط دارد. اين يافته نيز بافيز

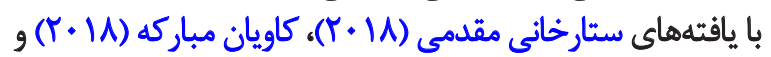

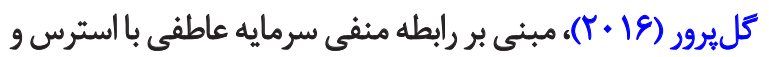

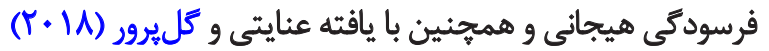

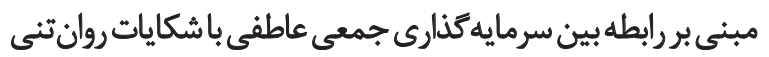

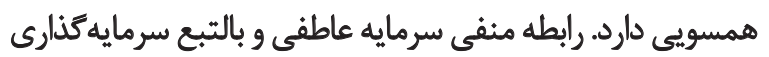

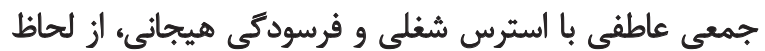

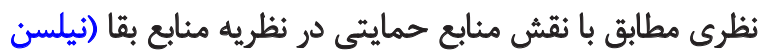

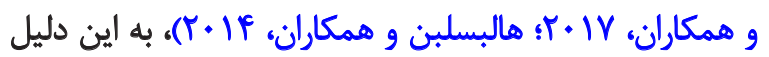

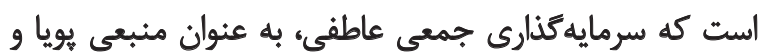

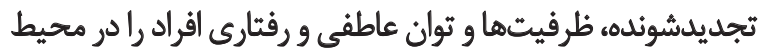

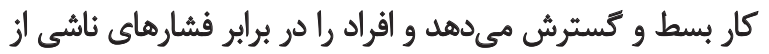

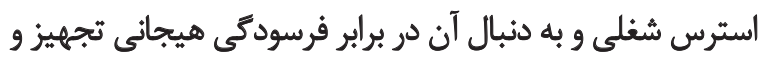

17. Addison, Yankyera

18. Aronsson

19. Dreison

20. Cui

21. Monsalve-reyes 
استفاده شد. در اين راستا نيز توصيه مي شود در مطالعات آينده

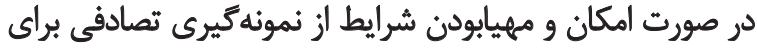

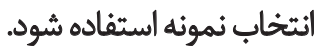

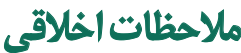

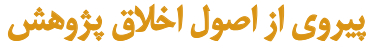

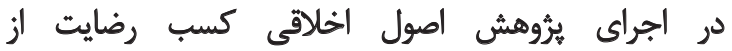

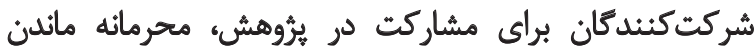

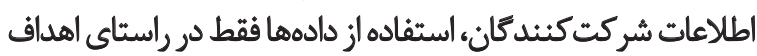

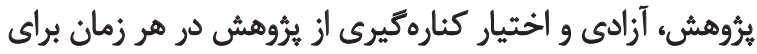

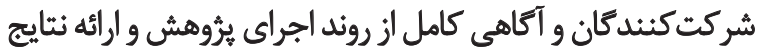

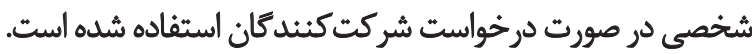

$$
\text { ماهي مالب }
$$

اين مقاله كه برترفته از باياننامه كارشناسىارشد رشته

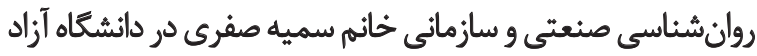

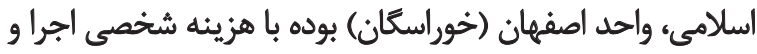

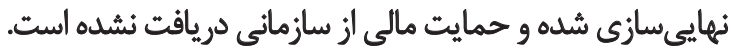

$$
\text { مشاركت نويسند مكان }
$$

مشاركت نويسندكان به شرح زير است: مفهومسازى: محسن

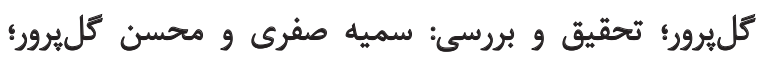
ويراستارى و نهايیىسازى نوشته: محسن كليرور.

$$
\text { تعارض مثافع }
$$

هيج گونه تعارض منافعى براى اين يثروشش از سوى نويسندًان

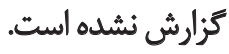

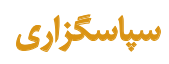

در بايان از تمامى كاركنان و مديران شركت قند در شهر إربان

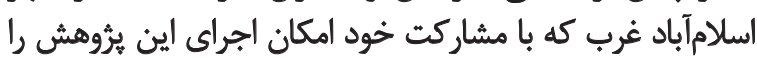

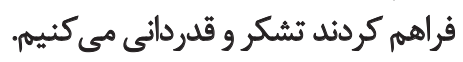

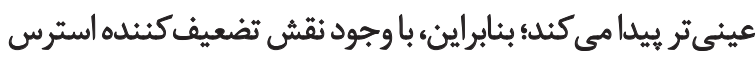

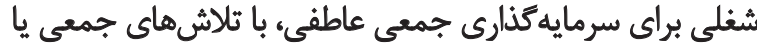

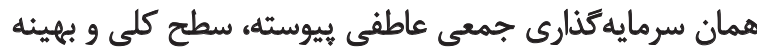

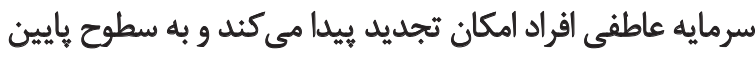

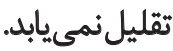

نكثه دوم كه مكمل نكثه اول در زمينه تبيين است، به اين

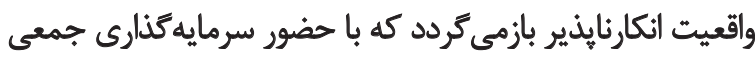

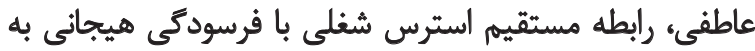

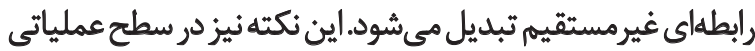

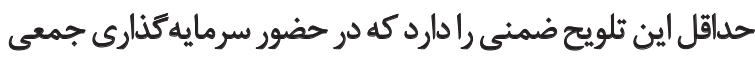

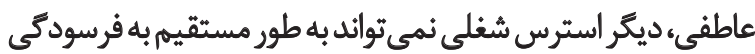

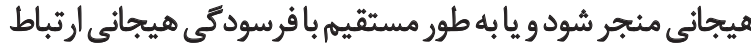

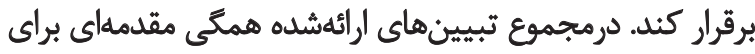

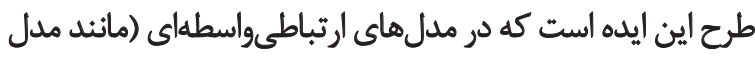

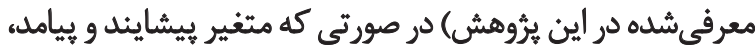

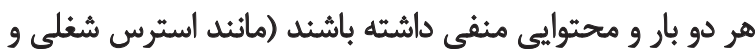

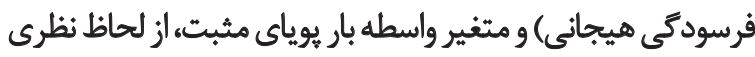

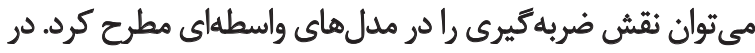

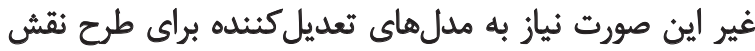

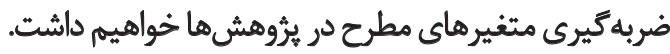
در اين يُروهش اين نتيجه كيرى كلى را مى توان مطرح كرد كهي

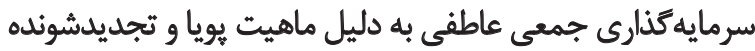

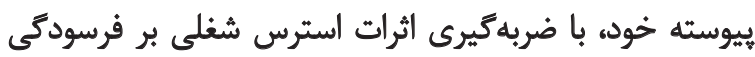

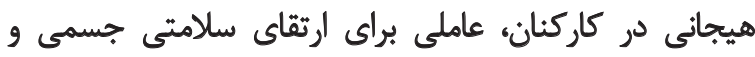

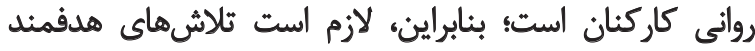

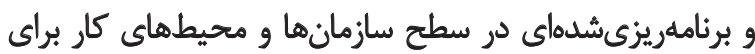

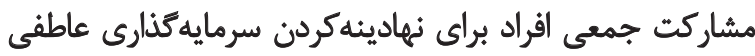

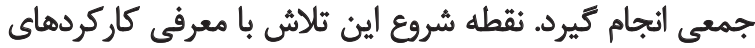

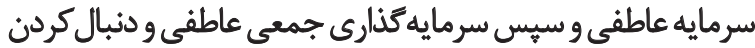

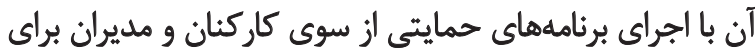
يكديكر ارتباطى تناتنك دارد.

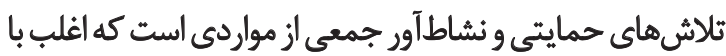

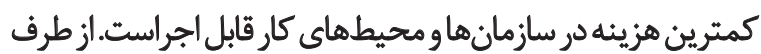

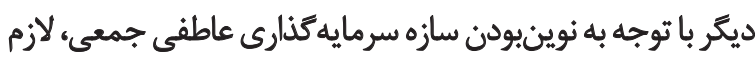

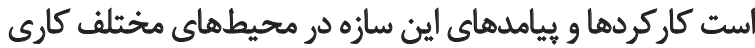

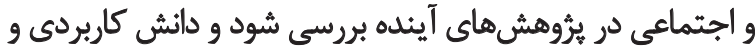

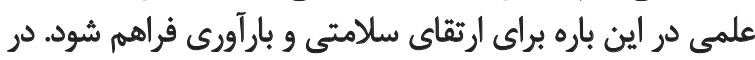

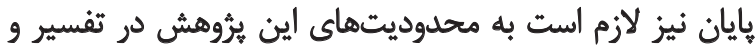

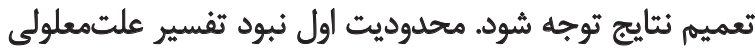

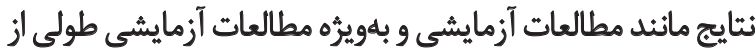

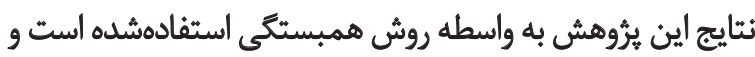

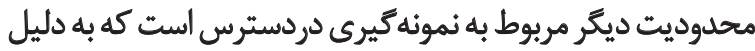

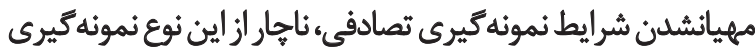


References

Addison, A. K., \& Yankyera, G. (2015). An investigation into how female teachers manage stress and teacher burnout: A case study of west Akim municipality of Ghana. Journal of Education and Practice, 6(10), 1-24.

Ahmadpour Torkamani, M. (2018). [The structural pattern of the relationship between honest leadership with emotional collective investment, civic-organizational behaviors, and job performance (Persian)] [MSc. Thesis]. Khorasgan, Isfahan: Islamic Azad University.

Aronsson, G., Theorell, T., Grape, T., Hammarström, A., Hogstedt, C., Marteinsdottir, I., et al. (2017). A systematic review including meta-analysis of work environment and burnout symptoms. BMC Public Health, 17, 264. [DOI:10.1186/s12889-017-4153-7] [PMID] [PMCID]

Asamoah-Appiah, W., \& Aggtey-Fynn, I. (2017). The impact of occupational stress on employee's performance: A study at Twifo oil palm plantation limited. African Journal of Applied Research, 3(1), 14-25.

Basińska, B. A., \& Gruszczyńska, E. (2017). Positivity and job burnout in emergency personnel: Examining linear and curvilinear relationship. Polish Psychological Bulletin, 48(2), 212-9. [DOI:10.1515/ppb-2017-0024]

Basińska, B. A., Wiciak, I., \& Maria Dåderman, A. (2014). Fatigue and burnout in police officers: The mediating role of emotions. Policing: An International Journal of Police Strategies \& Management, 37(3), 665-80. [DOI:10.1108/PIJPSM-10-2013-0105]

Cui, Q., Chao, Q., Han, J., Zhang, X., Ren, Y., \& Shi, J. (2018). Job stress, burnout and the relationship among the science and mathematics teachers in basic education schools. Eurasia Journal of Mathematics, Science and Technology Education, 14(7), 3235-44. [DOI:10.29333/ejmste/85957]

Day, A., Hartling, N., \& Mackie, B. (2015). The psychologically healthy workplace: Fostering employee well-being \& healthy businesses. In P. Perrewe \& J. Meurs (Eds.), Stress and Quality of Working Life (pp. 199-217). Charlotte: Information Age Publishing. [PMID] [PMCID]

Dreison, K. C., Luther, L., Bonfils, K. A., Sliter, M. T., McGrew, J. H., \& Salyers, M. P. (2018). Job burnout in mental health providers: A meta-analysis of 35 years of intervention research. Journal of Occupational Health Psychology, 23(1), 18-30. [DOI:10.1037/ocp0000047] [PMID]

Finne, L. B., Christensen, J. O., \& Knardahl, S. (2016). Psychological and social work factors as predictors of mental distress and positive affect: A prospective, multilevel study. PLOS One, 11(3), e0152220. [DOI:10.1371/ journal.pone.0152220] [PMID] [PMCID]

Gholamhosseini, M., Keivanzadeh, M., Arjmand, N. (2008). (Spirituality, job stress, organizational commitment, and job satisfaction among nurses in Tehran (Persian)]. Contemporary Psychology, 3(2), 61-73.

Golparvar, M. (2016). Unconventional functions of deviant behaviors in the relationship between job stress and emotional exhaustion: Three study findings. Current Psychology, 35(3), 269-84. [DOI:10.1007/s12144-0149292-8]

Golparvar, M. (2017). [Emotional capital: Functions and needs (Persian)] Tehran: Jangal.

Golparvar, M. (2018). [Applied measurement in organizational psychology (Persian)]. Khorasgan, Isfahan: Islamic Azad University.

Golparvar, M., Enayati, M. (2018). [Structural model of the relationship between affective-collective investment with affective capital and psychosomatic complaints among nurses (Persian)]. Journal of Nursing Education, 7(3), 57-64
Golparvar, M., Kamkar, M., \& Javadian, Z. (2012). Moderating effects of job stress in emotional exhaustion and feeling of energy relationships with positive and negative behavioral outcomes: Introducing the job stress multiple functions approach. International Journal of Psychological Studies, 4(4), 99-112. [DOI:10.5539/ijps.v4n4p99]

Golparvar, M., Mohsenzadeh, S., Raie, A., \& Abdi, A. (2016). [Moderating role of the deviant behaviors on the relationship between job stress and perceived psychological safety (Persian)]. Contemporary Psychology, 10(2), 83-100

Halbesleben, J. R. B., Neveu, J. P., Paustian-Underdahl, S. C., \& Westman, M. (2014). Getting to the "COR": Understanding the role of resources in conservation of resources theory. Journal of Management, 40(5), 1334 64. [DOI:10.1177/0149206314527130]

Hashemi, S. E., Savadkouhi, S., Naami, A., \& Beshlideh, K. (2018). Relationship between job stress and workplace incivility regarding to the moderating role of psychological capital. Journal of Fundamentals of Mental Health, 20(2), 103-12.

Kavian Mobarake, N. (2018). [Structural pattern of relationship between job stress and emotional exhaustion with emotional capital, performance and job success (Persian)] [MSc. Thesis]. Khorasgan, Isfahan: Islamic Azad University.

Khan, F. I., Rosman, M. D., Yusoff, I., \& Khan, A. (2014). Job demands, burnout and resources in teaching a conceptual review. World Applied Sciences Journal, 30(1), 20-28.

Martinez, S. A., Beebe, L. A., Thompson, D. M., Wagener, T. L., Terrell, D. R., \& Campbell, J. E. (2018). A structural equation modeling approach to understanding pathways that connect socioeconomic status and smoking. PLoS One, 13(2), e0192451. [DOI:10.1371/journal.pone.0192451] [PMID] [PMCID]

Maslach, C., \& Jackson, S. E. (1981). The measurement of experienced burnout. Journal of Occupational Behavior, 2(2), 99-113. [DOI:10.1002/ job.4030020205

Mitchell, T. R. (2018). A dynamic, inclusive, and affective evolutionary view of organizational behavior. Annual Review of Organizational Psychology and Organizational Behavior, 5, 1-19. [DOI:10.1146/annurevorgpsych-032117-104425]

Monsalve-Reyes, C. S., San Luis-Costas, C., Gómez-Urquiza, J. L., AlbendínGarcía, L., Aguayo, R., \& Ca-adas-De la Fuente, G. A. (2018). Burnout syndrome and its prevalence in primary care nursing: A systematic review and meta-analysis. BMC Family Practice, 19, 59. [DOI:10.1186/s12875018-0748-z]

Nastiezaie N, Sabegi F. (2016). [Relationship between extreme dependence to work with job stress and job burnout in teachers (Persian)]. Iran Oce cupational Health, 13(2), 79-91.

Nielsen, N., Nielsen, M. B., Ogbonnaya, C., Känsälä, M., Saari., \& laksson, K. (2017). Workplace resources to improve both employee well-being and performance: A systematic review and meta-analysis. Work \& Stress, 31(2), 101-20. [DOI:10.1080/02678373.2017.1304463]

Norouzi, R., Dargahi, S., Aeyadi, N., \& Sarhaddi, M. (2018). The association between workplace spirituality and job stress with occupational ethics through mediating role of job enthusiasm among nurses in Zahedan city, 2017. Journal of Occupational Health and Epidemiology, 7(1), 3-10. [DOI:10.29252/johe.7.1.3]

O'Connor, K., Muller Neff, D., \& Pitman, S. (2018). Burnout in mental health professionals: A systematic review and meta-analysis of prevalence and determinants. European Psychiatry, 53(8), 74-99. [DOI:10.1016/j.eurpp sy.2018.06.003] [PMID] 
Prabha, K. S., \& Sandeep, K. (2016). Positive affectivity as a moderator of occupational stress and ill-health. Indian Journal of Health \& Wellbeing, $7(1), 41-4$.

Raman, P., Sambasivan, M., \& Kumar, N. (2016). Counterproductive work behavior among frontline government employees: Role of personality, emotional intelligence, affectivity, emotional labor, and emotional exhaustion. Journal of Work and Organizational Psychology, 32(1), 25-37. [DOI:10.1016/j.rpto.2015.11.002]

Rezaei, S., Karami Matin, B., Hajizadeh, M., Soroush, A., \& Nouri, B. (2018). Prevalence of burnout among nurses in Iran: A systematic review and meta-analysis. International Nursing Review, 65(3), 361-9. [DOI:10.1111/inr.12426] [PMID]

Rydstedt, L. W., Johnsen, S.K., Lundh, M., \& Devereux, J. J. (2013). The conceptual roles of negative and positive affectivity in the stressor-strain relationship. European Journal of Psychology, 9(1), 93-103. [DOI:10.5964/ ejop.v9i1.537]

Salvagioni, D. A. J., Melanda, F. N., Mesas, A. E., GonzaÂlez, A. D., Gabani, F. L., \& Andrade, S. Md. (2017). Physical, psychological and occupational consequences of job burnout: A systematic review of prospective studies. PLOS One, 12(10), e0185781. [DOI:10.1371/journal.pone.0185781] [PMID] [PMCID]

Satarkhani Moghadam, N. (2018). [Relationship between job stress and innovative behaviors and civic-organizational behaviors with respect to the role of intermediary of emotional capital (Persian)] [MSc. Thesis]. Khorasgan, Isfahan: Islamic Azad University.
Siegrist, J., \& Li, J. (2018). Work stress and the development of chronic diseases. International Journal of Environmental Research and Public Health, 15(3), 536. [DOI:10.3390/ijerph15030536]

Thian, J. H. M., Kannusamy, P., He, H. G., \& Klainin-Yobas, P. (2015). Relationships among stress, positive affectivity, and work engagement among registered nurses. Psychology, 6(2), 159-67. [DOI:10.4236/ psych.2015.62015]

Wang, J., \& Wang, X. (2012). Sample size for structural equation modeling. In J. Wang, \& X. Wang (Eds.), Structural Equation Modeling: Applications Using Mplus. Hoboken: John Wiley \& Sons. [DOI:10.1002/9781118356258]

Warr, P., Bindl, U. K., Parker, S. K., \& Inceoglu, I. (2014). Four-quadrant investigation of job-related affects and behaviors. European Journal of Work and Organizational Psychology, 23(3), 342-63. [DOI:10.1080/135943 2X.2012.744449

Yang, T., Shen, T., Zhu, M., Liu, Y., Deng, J., Chen, Q., et al. (2016). Effects of co-worker and supervisor support on job stress and presenteeism in an aging workforce: A structural equation modeling approach. International Journal of Environmental Research and Public Health, 13(1), 72.

Yorulmaz, Y. İ., \& Altnkurt, Y. (2018). The examination of teacher burnout in Turkey: A meta-analysis. Turkish Journal of Education, 7(1), 34-54. [DOI:10.19128/turje.348273] 
This Page Intentionally Left Blank 